\title{
LÍNGUAS MATERNAS: SOBRE A CONVIVÊNCIA DO JUDEU-ESPANHOL COM O HEBRAICO EM ISRAEL ${ }^{1}$
}

\author{
Michal Held*
}

\section{Resumo}

Este artigo dispõe-se a explorar e interpretar narrativas pessoais de mulheres falantes do judeu-espanhol, criadas na atmosfera cultural e linguística na atualidade israelense. A pesquisa é baseada num enfoque que define a narrativa pessoal como multifacetada e portanto utiliza ferramentas multidisciplinares para examinar o material coletado numa perspectiva linguística, literária, folclórica, antropológica e sociológica. As narrativas, assim como a atividade do grupo que serve de estrutura conceitual devem ser considerados à luz da definição de Benedict Anderson para uma "comunidade imaginária", como a reconstrução do imaginário do judeu-espanhol, tido como uma identidade imaginária baseada numa cultura que virtualmente não tem função hoje em dia. Do aspecto da etnicidade a principal questão é se e como as narrativas pessoais criadas por mulheres falantes do judeu-espanhol aqui e agora refletem a identidade coletiva e as concepções do grupo étnico sefardita.

Palavras-chave: judeu-espanhol, ladino, identidade, sefarditas, hebraico

\begin{abstract}
This paper sets out to explore and interpret the personal narratives of Judeo-Spanish speaking women, created in the linguistic and cultural climate of contemporary Israel. The research is anchored in an approach that defines the personal narrative as multi-faceted, and it therefore uses multidisciplinary tools to examine the narratives collected from linguistic, literary, folkloristic, anthropological and sociological perspectives. The personal narratives analyzed, as well as the group activity that serves as their conceptual framework, may be regarded in the light of Benedict Anderson's definition of an "imagined community", as the reconstruction of a Judeo-Spanish imaginary identity based on a culture that has virtually no function in today's world. From the aspect of ethnicity, the leading question is if and how the personal narratives created by Judeo-Spanish speaking women here and now reflect the collective identity and

\footnotetext{
${ }^{1}$ Tradução de Diego Raigorodsky.

* Autora, professora e pesquisadora vinculada ao Centro de Pesquisa sobre Língua e Literatura Judaica da Universidade Hebraica de Jerusalém. <msmheld @ mscc.huji.ac.il>
} 
conceptions of the Sephardic ethnic group.

Keywords: Judeo-Spanish, Ladino, identity, Sephardic,Hebrew language

\section{Introdução}

Por mais de vinte anos, e até recentemente, eu encontrei em Jerusalém um grupo de mulheres que contavam entre si narrativas populares em judeu-espanhol (Ladino) ${ }^{2}$ - idioma que, hoje em dia, quase deixou de ser uma língua falada. As contadoras são descendentes de comunidades judaico-espanholas que passaram a existir no Império Otomano após a expulsão da Ibéria no final do século XV e floresceram até o começo do século XX. ${ }^{3}$ Embora hoje sua vida seja toda feita em hebraico em Israel, essas mulheres não conseguem se desvencilhar da cultura judaico-espanhola. Matilda Koen-Sarano, que promoveu o surgimento do grupo e que hoje o dirige, reuniu diversas narrativas populares das contadores e as publicou por escrito em judeu-espanhol (JE) e em tradução ao hebraico. ${ }^{4}$ Ao contrário das narrativas populares contadas pelas mulheres do grupo, as narrativas pessoais de cada uma delas ainda não foi reunida e nem compilada em forma final. Durante minha pesquisa de doutorado preparei um trabalho de campo no qual as contadoras concordaram com o meu pedido de me contar sobre elas mesmas. ${ }^{5}$

Neste artigo, focarei a troca de código - um dos fenômenos linguísticos que se revelou nas narrativas pessoas que pesquisei - e tecerei considerações a respeito do significado por trás dele. Código (code) é a parte do idioma usada para estabelecer uma relação com um grupo específico. Por exemplo: o hebraico vs. outros idiomas; o hebraico dos soldados no exército vs. o hebraico deles em contextos diferentes. ${ }^{6}$ Disso decorre que a troca de código

\footnotetext{
2 O judeu-espanhol é essencialmente uma língua românica, que possui também bases hebraicas, aramaicas, árabes, turcas e balcânicas. Sua origem remonta à Espanha da Idade Média, e ela se tornou uma das línguas judaicas mais conhecidas quando os expulsos da Espanha e seus descendentes continuaram a utilizá-la por escrito e oralmente nas comunidades que foram fundadas depois da expulsão Ibérica de 1492. Ao longo dos anos a língua foi chamada de diversos modos. O nome "Ladino", o mais usado atualmente, em sua origem era o termo usado para se referir exclusivamente ao idioma judeu-espanhol usado nas traduções do Tanach e da literatura sagrada a partir do século XV. Por ser uma língua utilizada para textos e com intenções tradutórias (bem como por outros aspectos), o ladino é diferente da língua falada e escrita pelos judeus espanhois que não tinha ligação com a literatura sagrada. É por esse motivo que o idioma usado para relatar as narrativas pessoais citadas nesse artigo será referido como "judeu-espanhol" (daqui em diante, JE).

3 A respeito das comunidades judaicas no Império Otomano após a expulsão, cf., por exemplo, Benbassa e Rodrigue.

4 Koen-Sarano, Joha; __ _, Konsejas; __ _ Lejendas; __ , Kurtijo.

5 Held, Boi.

6 Rodrigue-Schwarzwald e Sokolov, p. 37.
} 
(code switching) é a mudança do uso de um código linguístico para outro código linguístico dentro do contexto de uma mesma conversa produzida por um mesmo falante.

As contadoras populares cujas narrativas pessoais investiguei em minha pesquisa dominam o JE como língua materna, e as narrativas registradas relatadas por elas são quase que exclusivamente provenientes de um discurso oral e corrido nesse idioma. No entanto, os vários anos vivendo em um ambiente linguístico hebraico tradicional e moderno, além do fato de elas estarem relatando suas narrativas pessoais para uma pessoa que representa a entidade israelense de nossa época, deixaram suas marcas na linguagem delas. Além da mistura de elementos hebraicos isolados em sua fala, em alguns casos as informantes interromperam o seu discurso em JE e passaram a falar trechos relativamente longos em hebraico. ${ }^{7}$ Baseandose nas definições de Carol Mayers-Scotton, pode-se, de fato, dizer que a língua matricial (matrix language) delas é o JE, e que a língua embutida nelas (embedded language) é o hebraico. ${ }^{8}$

Gumperz e Blom defendem a diferenciação entre a troca de códigos situacional (situational switching) e a troca de códigos metafórica (metaphorical switching). ${ }^{9}$ No primeiro caso, a troca de código linguístico é feita com base em uma mudança na situação de fala; enquanto que, no segundo caso, não ocorre mudança na situação, e a troca de código se baseia no conteúdo que o falante deseja transmitir por meio da fala e da conversação. Esse modelo é relevante para a discussão do diálogo central em minha pesquisa: cada um dos encontros entre mim e as contadoras de história é uma situação conversacional única e coesa que não aceita troca de código. Os códigos linguísticos trocados na boca das informantes durante esses encontros não são um evento situacional, e sim um evento metafórico, que atestam algo a respeito da mensagem que as informantes desejam transmitir através de suas narrativas pessoais e a respeito da identidade pessoal expressa nelas. Segundo Blom e Gumperz:

\footnotetext{
Nesse artigo focarei na troca de código e não poderei explicar os empréstimos de elementos hebraicos isolados - um fenômeno que a maior parte do capítulo linguístico de meu trabalho de doutorado e o livro que foi publicado em seguida tem intenção de descrever e explicar (cf. nota 4 anterior, p. 219-263).

8 Mayers-Scotton, p. 4.

9 Blom e Gumperz.
} 
A mudança lingüística que ocorre aqui refere-se a questões de tipos específicos, e não a mudanças na situação social. Situações desse tipo se caracterizam por permitirem que dois ou mais sistemas de relações sejam representados entre os detalhes. ${ }^{10}$

A pesquisa de troca de código se desenvolveu na segunda metade do século $\mathrm{XX}$, depois da teoria pioneira de Uriel Weinreich a respeito do fenômeno de contato entre as línguas. ${ }^{11}$ Peter Auer defende que a troca de código pode ser analisada de três aspectos: o aspecto sintático, o aspecto interacional dos falantes e o aspecto social. ${ }^{12}$ Monica Heller escolheu o terceiro aspecto e definiu um objetivo para uma pesquisa futura:

A necessidade etnográfica da comunicação com base em uma análise dividida em dois ramos: uma descrição do papel da troca de código no repertório de informações e a descrição dessas informações e do uso que elas causam na troca de código nas redes sociais da comunidade. ${ }^{13}$

Segundo Shana Poplack, é preciso ampliar a posição investigativa aceita de que a troca de código é uma escolha de caminho, ideia essa que se baseia em uma compreensão social e pragmática, abrindo-a por meio de um modelo que considere causadores funcionais e linguísticos que refletem de forma mais abrangente o comportamento linguístico cuja essência é a troca de código, pois trata-se de um fenômeno de aspectos diversificados: a respeito de como a gramática e de como as atitudes em relação à etnia e identidade são determinadas pelo comportamento lingüístico. ${ }^{14}$ Essas posições de pesquisa são a base para as observações da troca de código ocorridas nas narrativas pessoais que me foram relatadas. Depois delas, eu gostaria de definir o fenômeno lingüístico diante de nós também como uma estrutura que esclarece o conteúdo do discurso no qual ele está inserido. Como mencionado, vejo na troca de código ocorrida nos relatos das narrativas pessoais dessas mulheres uma estratégia narrativa e hermenêutica. Como etapa adicional da pesquisa mencionada anteriormente, sugiro a possibilidade de ampliar a compreensão da troca de código situando-a em um contexto que não se vê limitado pela lingüística.

Devido à falta de espaço não é possível mencionar aqui todas as ocorrências de troca de código que documentei com as informantes, mas pode-se analisar alguns exemplos que considerei particularmente interessantes. Há pesquisadores de JE que sugeriram que a troca de

\footnotetext{
${ }^{10}$ idem, p. 425.

${ }^{11}$ Sobre a história de pesquisa sobre o bilinguismo e a troca de código e seu valor, cf. Milroy e Muysken,p. 4-10; Mayers-Scotton, p. 45-74 e a reavaliação de Auer.

12 Auer, Bilingual Conversation, p. 1.

${ }^{13}$ Heller, p. 266.

${ }^{14}$ Poplack, p. 585.
} 
código ocorrida no discurso judaico-espanhol contemporâneo indica o pouco conhecimento de JE por parte dos falantes. ${ }^{15}$ No entanto, como mencionado, as informantes cuja troca de código examinarei adiante possuem domínio nativo do JE. Assim, o conceito que orientou a ideia de passagem entre um idioma e outro ratifica a ideia de que a troca de código é uma troca simbólica e narrativa que permite às contadoras enfatizar a narrativa e destacar o seu conteúdo.

\section{Interpretação da troca de código na fala das informantes}

A seguir analisarei a troca de código no discurso de três das informantes que entrevistei, e me focarei em trechos de discurso que compartilham um conteúdo comum: todos são relacionados à relação das falantes com a mãe e/ou com os filhos. Da leitura atenta dos trechos relevantes do discurso fica claro que a questão das relações entre mães e filhas e entre filhas e mães, como refletido no discurso das informantes, indica o potencial oculto na análise meticulosa da troca de código como fenômenos estruturais que refletem camadas de significado e conteúdo, e nas chaves interpretativas centrais para as narrativas nas quais ela está inserida. O fato de que muitas trocas de código ocorreram nos pontos das narrativas em que as informantes descreviam suas mães (e às vezes suas filhas) indica o tema central da maternidade em sua concepção de si mesmas e de suas vidas.

\section{Troca de código na história de Ester Levi ${ }^{16}$}

A informante Ester Levi domina bem o JE, e, em geral, não depende do hebraico para se expressar com fluência na língua de sua mãe. Ester foi exposta por muitos anos a um ambiente falante de hebraico-israelense moderno, e seu JE se manteve com ela em um nível infantil e enriquecido por elementos hebraicos israelenses. Prova do domínio de Ester do JE é o fato de que quando uma pergunta lhe é feita em hebraico ela responde de maneira espontânea na língua usada para formular a pergunta, mas logo depois volta a discursar em

${ }^{15}$ Uma ideia desse tipo é defendida por Tracy Harris, p. 443-444: “[...] a troca de código ou a mudança interlinguística em JE de fato reflete uma degeneração linguística. As trocas ocorrem pois os falantes não conhecem as palavras ou expressões correspondentes em JE.

${ }^{16}$ Nasceu em Jerusalém em 1920, onde mora desde então. Fala JE, hebraico, árabe, francês e inglês. 
JE, a língua que estava usando para relatar sua história. Trarei dois exemplos desse fenômeno: ${ }^{17}$

Michal: Zê lô meshanê et hachaim? (Isso não muda a vida?)

Ester: Lo! Kol echad lefi ma shenolad. Si eramos ashkenazis diziamos: na, es bueno 'star 'shkenazi (Não! Cada um conforme nasceu. Se nós fossemos ashkenazis, diríamos: olha, é bom ser ashquenazi). ${ }^{18}$

Michal: Aval hachaim haiu tovim (Mas a vida era boa).

Ester: Ken, beseder. Ma sheani haiti omeret. Baali haia kaze, era mui bueno ombre. No le plazia diskutir (Sim, concordo. É isso que eu estava dizendo. Meu marido era assim, era um homem muito bom. Ele não gostava de discutir).

Assim, Ester não está isolada do seu ambiente linguístico hebraico, mas o mistura em seu JE conforme a necessidade. Algumas vezes ela volta ao hebraico em uma frase que está falando em JE para esclarecer ou enfatizar alguma coisa. Assim, por exemplo, no começo da entrevista ela se apresenta dizendo:

Me yamo Ester Levi, nasi a la kompania de Yemin Moshê, Yerushalayim, en 1920. Ani ielidat shmone iuli elef tshá meot esrim. I me plaze muncho kontar konsejas. (Meu nome é Ester Levi, nasci no bairro de Iemin Moshê, em Jerusalém, em 1920. Nasci em oito de julho de 1920. Eu gosto muito de contar contos).

O registro do discurso direto de trechos ditos por falantes de outras línguas é um processo complexo que pode ocorrer de duas maneiras. A primeira é o caso em que a informante faz citações de pessoas que não dominam o JE. Então, citam-se as palavras na língua desses falantes - o hebraico. Assim, por exemplo:

Mui ermozo. A mi me plaze mirar 'stampas. La tadre ya m'asento [i] vo mirar las 'stampas. Essa (aponta para uma das fotos) hamishpachá sheli. Habanot sheli omrot: ima, at choneket et haalbom! (Muito bonito. Eu gosto muito de olhar fotografias. À tarde eu me sento e vou olhar fotos. Esta (aponta para uma das fotos) é minha família. Minhas filhas dizem: mãe, você está sufocando o álbum!)

Nesse caso, a frase dita antes de citar o discurso direto - "esta é minha família" também foi dita em hebraico, e o trecho todo da troca de código mostra que na visão de mundo da informante a geração posterior da sua família já pertence ao ambiente israelense, ao hebraico moderno, e não à parte tradicional judaico-espanhola que faz parte do seu mundo

\footnotetext{
17 Ao longo do artigo, a fala das informantes aparece sempre transliterada, seja em JE, seja em hebraico, com a diferença que, para este último idioma, a transcrição aparece em negrito. Logo a seguir aparece a tradução entre parênteses, onde, novamente, o que foi dito em hebraico aparece em negrito (N. T.).

18 Até o século XX o JE era escrito com o alfabetro hebraico e as letras do alfabeto Rashi. Recentemente, a maioria dos leitores e escritores, em Israel e no mundo, adotaram o sistema de escrita estrangeiro, chamado de Aki Yerushalayim, e que também será usado nas transcrições deste artigo. Para mais detalhes sobre a transcrição, confira o Anexo.
} 
pessoal.

O outro tipo de citação que Ester Levi usa reflete as palavras de falantes com quem ela costumava falar em JE, mas em seus relatos pessoais ela revisita as conversas e cita as palavras dessas pessoas em hebraico:

I kuando mi marido se murio, me desho una letra. Disho: Ester, todá rabá, ani modê lach al hatipul. Vehaieladim, ani mevakêsh mikem shetetaplu beima ad haiom haacharon. Michtav. Mi marido. Vino aki un orêh din, izo tsavaa, izo todo. (E quando meu marido morreu, me deixou uma carta. Ele disse: Ester, muito obrigado. Agradeço os cuidados. $E$ quanto às crianças, eu peço que cuidem da mãe até o último dia! $A$ carta. Meu marido. Veio aqui um advogado, fez o testamento, fez tudo).

Ester indica em outro ponto de sua história que ela costumava falar com o seu marido em JE quando eram jovens e quando viviam em um ambiente falante de JE, bem como em anos posteriores, quando passaram a viver em um ambiente falante de hebraico. A isso se soma o fato de que em sua história pessoal ela cita em hebraico as palavras que seu marido disse antes de morrer, mesmo não sendo esse o idioma de uso em sua vida conjunta. A mudança linguística é usada aqui como estratégia narrativa, e a troca ocorrida na conversa em JE com o marido para o hebraico simboliza o distanciamento. Esse é um evento que simboliza uma mudança na vida da informante: o final de uma época conhecida, tradicional e certa, e o começo de um período novo e desconhecido. O uso do hebraico em uma situação pouco natural - no diálogo entre a mulher e seu marido prestes a morrer - enfatiza o sentimento de mudança, e também fortalece a mensagem que, aos olhos de Ester, o seu marido está abandonando-a em seu leito de morte: trata-se de uma mensagem na qual estão ilustradas as ferramentas que lhe permitirão continuar a viver e se sustentar depois de sua morte, já em um mundo israelense moderno. Além disso, o marido de Ester faz um pedido final aos filhos; portanto, essa parte do discurso foi feita em hebraico, que é o idioma que permeia o mundo das crianças.

Daqui chega-se ao aspecto da troca de código que gira ao redor da questão da maternidade, que é o foco deste artigo. A análise ao redor da palavra ima (mãe, em hebraico) na história de Ester demonstra como a informante enxerga a transição do JE para o hebraico, e vice versa. Quando ela se refere às mães presentes na entrevista (que, do ponto de vista dela, são mães neutras por oposição à sua mãe ou a ela mesma como mãe) Ester usa, para se referir ao conceito de "mãe", a palavra francesa que se instalou em seu JE, e chega até mesmo a pronunciá-la de modo afrancesado [ma'ma]: "I agora 'sto en mi kaza, i 'sto kon Mihal i la mama (e agora estou na minha casa, e estou com a Michal e a mãe [dela]).” 
O nível de intimidade aumenta quando Ester conta sobre sua infância e descreve cenas ligadas à sua mãe. Nesses relatos a mãe é chamada pelo termo espanhol, "madre":

No vinia la madre muestra a tomarmos, no avia tiempo. Mos tornavamos solas. Kuando eskapavamos la eskola, vinia una vizina, una tia ke tenia un mansevo de konoser, i le dizia a mi madre: "Mira, yo tengo mansevo ke es lavorante bueno, ke es de famiya, i si keres te lo puedo konoser para tu ija. (Nossa mãe não veio nos pegar na escola, não havia tempo. Voltamos sozinhas. Quando terminamos a escola, veio uma vizinha, uma senhora que tinha um moço para apresentar [para casar comigo], e disse para minha mãe: "olha, eu tenho um moço que é bom trabalhador e um homem de família, e se você quiser posso apresentá-lo à sua filha).

Como esperado, a palavra hebraica ima aparece na boca de Ester quando ela descreve como suas filhas a chamam, pois as filhas cresceram em um mundo hebraico-israelense:

Mis ijas tyenen un armario de kundurias a kada una! Armario! Digo: "para kualo este todo?" "Ima, agora es ansina, no es komo kuando eras tu chika. Este modo es agora, otra vida. (Minhas filhas, cada uma delas tem um armário de sapatos! Um armário! Eu digo: "pra que tudo isso?" [Elas respondem]: "Mãe, agora é assim, não é mais como quando você era pequena. Agora é assim que funciona. É outra vida".)

Nesse trecho o uso do termo hebraico reforça o conteúdo da frase: segundo a visão de mundo da falante, suas filhas querem transmitir uma mensagem de que o mundo moderno israelense é diferente do mundo que ela conheceu em sua infância. Assim, nada mais natural que essa mensagem seja expressa de modo que ela seja chamada de ima, em hebraico. Justamente essa palavra, que é tão primordial ao ser humano, e tão importante no processo de construção da identidade promovido pela linguagem (não é por acaso que se fala em "língua materna", ou termos paralelos em outros idiomas), aparece no discurso de Ester Levi de forma surpreendente: "Le dizia a mi madre: 'Ima, haiom me kero durmir ande la vava"19'. (Disse para minha mãe: Mãe, hoje eu quero dormir na vovó)."

Essa frase foi dita dentro de um trecho de diálogo no qual a informante descreve a sua infância na cidade velha de Jerusalém, em uma época na qual o JE era a língua de casa e das ruas. Justamente ligado a isso, o tratamento que Ester Levi criança - o qual nos dá uma imagem da Ester Levi adulta -, dispensa à sua mãe, se dá pelo termo hebraico ima, prova e exemplo das ferramentas misturadas que existem como parte do repertório linguístico impresso na fala das contistas populares, que falam JE no Israel de hoje em dia. Assim a troca de código atesta a visão de presente e de passado que acompanham a contadora, que vê em

${ }^{19}$ Do grego: avó. 
sua mãe uma figura presente em sua vida mesmo anos depois da morte.

Temos diante de nós uma mulher cuja primeira metade da vida (a infância e juventude) ocorreu em um ambiente linguístico judeu-espanhol. Desde seu casamento e até o presente, quando ela conta sua história pessoal, a informante viveu em um ambiente familiar e social cujo monopólio linguístico mudou do JE para o hebraico israelense moderno. A presença do JE se reduziu, mas ele continua existindo nos diálogos entre Ester e outros falantes de JE da mesma geração que ela, nos encontros com a família, e com o grupo de mulheres que compõem as contadoras de narrativas. Esse repertório linguístico não é apenas uma questão técnica.

Ele reflete o fato de que a visão de mundo da informante sobre si mesma e sobre o mundo ao seu redor se dá por meio de dois mundos linguísticos distintos. Esses mundos refletem, por sua vez, dois ambientes de vida físicos diferentes, e dois sistemas culturais distintos. São eles que aparecem e enriquecem a história de Ester. Ao descrever a sua infância ligada ao mundo judeu-espanhol, surgem lampejos hebraicos. E, ao mesmo tempo, a existência hebraica israelense é descrita com uma linguagem judaica que não existe mais como idioma falado no contexto maior da sociedade.

As ferramentas linguísticas mistas utilizadas no relato pessoal de Ester Levi enfatizam a temática da história como um todo. Uma história pessoal não é, por natureza, linear. Os eventos da vida são descritos de diferentes maneiras, entrelaçando-se quando são convertidos em estruturas orais e discursivas. Do ponto de vista linguístico, a troca de código atesta que o JE e o hebraico são dois fios que se entrelaçam no discurso da informante, formando um só fio condutor. E esse processo enfatiza o fato de que não existe o anterior e o posterior em um relato pessoal, mas a transformação do anterior e do posterior em um só fato que se desenrola no relato.

Da frase trazida anteriormente, salta aos olhos também o uso do termo hoje em hebraico (haiom), ${ }^{20}$ que é usado unido ao significado situacional linguístico e narrativo em que ele está inserido. A que tempo se refere esse termo? No nível manifesto, trata-se do presente do momento da história: a época da infância na qual a informante quer dormir na casa da avó. Mas a escolha terminológica dela mostra que se trata de uma rede temporal mais complexa: se

\footnotetext{
${ }^{20}$ Bunis não traz as palavras ima e haiom no seu léxico de elementos hebraicos tradicionais presentes no judeuespanhol. Em sua lista (cf. Bonis) aparece apenas o termo emahot (matriarcas, $\mathrm{n}^{\circ} 2189$ ) nas narrativas bíblicas (as quatro matriarcas) e algumas variantes tradicionais distintas ( $\mathrm{n}^{\circ}$ 1765-1779), que incluem a palavra iom (iom tov, iom hakipurim, iom hashishi, etc). Portanto, pode-se supor que essas palavras entraram no JE por meio do hebraico israelense moderno contemporâneo.
} 
se trata de um passado distante - um período no qual o presente era de uso e domínio do JE por que a informante utiliza a palavra hebraica haiom em seu relato? Não existe uma resposta simples e direta, mas, sem dúvida, ela nos leva à compreensão de que o discurso linguístico deixa entrever os elementos da vida e o fato de que toda tentativa de colocá-los em um relato também é um elemento em si.

$\mathrm{Na}$ troca de código é possível ver os divisores na superfície da água correndo nas profunidades daquilo que é a história pessoal. As pedras no percurso são indicadas por meio do enredo narrativo e influenciam ainda o seu fluxo. No caso que temos diante de nós, nota-se que a informante vê na sua mãe uma figura do mundo tradicional judeu-espanhol que já partiu, mas também uma figura viva dentro de sua filha no mundo israelense. Assim, a palavra haiom reflete a seus olhos tanto o presente como o passado, e em ambos os casos o fenômeno linguístico nos leva ao entendimento que o JE e o hebraico nada mais são do que dois níveis de conhecimento por meio dos quais a história da informante é relatada.

\section{Troca de código na história de Malka Simha ${ }^{21}$}

No discurso judeu-espanhol de Malka Simha, aparecem elementos de diferentes idiomas ligados a momentos de sua vida nos quais ela viveu em diferentes países, como Grécia, Turquia, França e Israel. Elementos dos idiomas desses ambientes, como o hebraico tradicional, parte inseparável do discurso judaico em cada um dos locais em que Málca viveu, dão um tempero especial ao JE da informante, sem fazer com que ele perca seu status de língua materna com força própria. Ao longo de seu relato pessoal, poucos são os casos nos quais a informante troca o seu fluente JE por hebraico. Por isso, de especial destaque é o trecho da conversa próximo ao final da entrevista com ela. Nesse trecho Málca fala de sua filha que faleceu dois anos antes do nosso encontro. A descrição da filha aparece na história depois de uma conversa sobre os costumes de Rosh Hashaná e sobre as comidas que os judeus sefaraditas costumam usar para fazer a bênção na noite da festa, na qual cada alimento simboliza uma virtude ou característica que as pessoas desejam ter consigo no ano que se inicia. Málca decide ler as leis relativas a essas bênçãos a partir do Machzor de Rosh Hashaná em Ladino, no qual alguns nomes dos alimentos mencionados aparecem em francês:

Aki no 'skrive rimon. Aki 'skrive... este es de aki (lendo): seder hasimanim leleil Rosh

21 Nascida na Grécia, em 1914. Morou na Grécia, Turquia e França. Imigrou para Israel em 1973 e passou a viver em Jerusalém até sua morte, no ano de 2010. Fala JE, hebraico, francês, grego e turco. 
Hashaná. Dag, pomme, poireau, ${ }^{22}$ salka... Salka ze selek. Poisson, ${ }^{23}$ grenad. ${ }^{24} \mathrm{Si}$, esto es d'aki. (Aqui não está escrito romã. Aqui está escrito... isso é daqui (lendo): ordem simbólica para a noite de Rosh Hashaná. Peixe, maçã, alho-poró, salka... Salka é beterraba, peixe, romã. Sim. Isso é daqui”.)

Logo depois dessa frase a informante de repente passa a falar de sua filha, sem que se tenha perguntado nada sobre ela, e de maneira desconexa com o que se vinha relatando até então. O relato sobre a filha é feito todo em hebraico, e com isso se estabelece uma clara separação entre a filha e o resto do relato pessoal da mãe:

Vou te contar. Ela [eu] tinha uma filha que morreu há dois anos. E com ela eu passei cinquenta anos de sofrimento. É uma história tão longa que eu não queria tocar nela. Mas eu superei isso na vida. Cada um tem sua própria história. Mas essas etapas, toda essa vida, cinquenta anos de sofrimento com ela, isso, isso é algo que, como Deus dá coragem e força para continuar vivendo? Hoje eu luto muito.

Não preciso dizer a minha idade. Vocês vêem que eu não sou nenhuma jovenzinha. Mas eu luto muito. E vou conseguindo. Eu não consigo caminhar, pegar uma bola. Me doi aqui, eu uso bengala. Eu tenho um tipo de carrinho quando eu quero sair. Sair para a feira. Ir fazer as compras.

Voltar para casa. Devagarinho. O que as crianças gostam eu cozinho para elas. As coisas difíceis eu faço aqui em casa, eu trago. Que Deus me dê o mérito de ter forças até o último momento, e de ser uma mulher ativa, para não precisar ser cuidada por ninguém. O que se pode fazer?

Assim como as outras informantes que relataram suas narrativas pessoais para a minha pesquisa, Malka Simcha também decidiu não colocar no centro da conversa as dificuldades de vida pelas quais passou, mas apenas indicar ou falar delas como se por acaso em meio ao relato como um todo. ${ }^{25} \mathrm{O}$ fato de ela ter uma filha que faleceu já era do meu saber antes de ela relatá-lo. E, apesar de tudo, o princípio que me conduziu em minha pesquisa era que o relato pessoal é uma criação humana formada e instaurada por palavras que a pessoa deseja usar, sendo que a pessoa é livre para eliminar dele partes específicas. Esse princípio me impediu de perguntar a ela mais detalhes sobre a filha. A informante, no entanto, optou por relatar essa parte da sua vida, como se vê, sem relação com o desdobramento do discurso ou com a ordem cronológica dos eventos de vida sendo narrados. Quando nosso encontro estava chegando ao fim, ela percebeu que não ia conseguir deixar a história completa se não

\footnotetext{
${ }^{22}$ Do francês: pomme, poireau.

${ }^{23}$ Do francês: poisson.

${ }^{24}$ Do francês: grenad.

25 Esse fato reflete uma característica da identidade judeu-espanhola de que a pessoa precisa superar as adversidades da vida e evitar se lamuriar ou falar delas com os outros. Discuti esse assunto em meu trabalho de doutorado dentro de um quadro de análise coerente das narrativas que preparei para analisar - e cujo uso é amplo em todas as narrativas pessoais que investiguei (cf. Held, Boi, p. 156-166). É de se esperar que o assunto seja analisado futuramente também sob um prisma antropológico e sociológico.
} 
incluísse a figura da filha. Como se a história de vida de uma mãe não se completaria caso nela não aparecesse a filha que viveu uma vida de sofrimento quando ainda jovem. A urgência em falar da filha, e não a ligação da história com ela, é o que fez que ela surgisse na história, e justamente a falta de ligação entre os temas é prova da força do relato sobre a filha.

Uma das coisas que destacam e reforçam o desenvolvimento temático relacionado com a descrição da imagem filha é a passagem do JE ao hebraico que ocorre nesse momento da história. Essa passagem ao hebraico serve como meio de criação literária: a história da filha é parte da história de vida de sua mãe, mas ela é isolada da história ao redor por se dar na língua hebraica, de maneira ressaltada contra todo o fluxo da história narrado em JE. A escolha da informante de incluir a história da filha em sua própria história, mas, ao mesmo tempo, deixando-a às margens do relato, removendo-a do contexto e expressando-a em hebraico e não em JE, cria simultaneamente uma dinâmica de proximidade e distanciamento: a história da filha é parte inseparável da história da mãe, mas é distinta dela no que diz respeito ao contexto e ao idioma. A informante usa aqui uma ferramenta linguística - a troca de código para expressar uma ideia narrativa que deriva de uma situação psicológica complexa. A dinâmica de afastamento e proximidade também é enfatizada por meio de um fenômeno linguístico adicional que ocorre nesse trecho: a fala da informante sobre si mesma na terceira pessoa (Vou te contar. Ela tinha uma filha que morreu há dois anos. E com ela eu passei cinquenta anos de sofrimento), algo que ela faz somente nesse ponto da história. $\mathrm{O}$ uso de terceira pessoa é característico do JE e não do hebraico moderno. Quando a informante usa essa forma narrativa em hebraico cria-se um sentimento de estranhamento. Esta é uma situação onde a forma aceita em JE é usada para expressar uma idéia em hebraico, e assim se ligam os dois mundos da mãe e da filha sendo descritos pela história - o mundo judeuespanhol e o mundo israelense.

Gumperz identificou no fenômeno da troca de código um elemento de contraste ou conflito, e o definiu deste modo: "o uso em um mesmo diálogo de passagens pertencentes a sistemas ou sub-sistemas de fala gramaticalmente diferentes". ${ }^{26}$ No presente contexto, essa definição é digna de ser expandida: nesse caso não se trata apenas de um conflito entre duas formas de fala pertencentes a diferentes sistemas sintáticos, mas também entre dois modos de diálogo que refletem o confronto interno entre atitudes emocionais polarizadas da informante. A introdução da filha falecida em hebraico de maneira destacada na história da mãe em que

${ }^{26}$ Gumperz, p. 59. 
todos os outros trechos são feitos em JE reflete a oscilação da informante entre diferentes forças: a incapacidade de aceitar a morte de sua filha, a incapacidade de contar sobre a morte e a incapacidade de não contar. Todos esses elementos são incorporados no comportamento verbal que vão muito além dos sistemas e sub-sistemas periféricos a que Gumperz se refere quando analisa o fenômeno da troca de código.

Depois de mencionar brevemente a filha falecida, Málca Simchá continua a contar sobre as dificuldades com que teve que lidar em sua vida, e logo depois ela me mostra fotos de seus filhos, netos e bisnetos. Os netos e bisnetos descritos próximos ao relato sobre a filha falecida expressam uma espécie de compensação pela perda, e também são apresentados em hebraico. Eu respondo em JE à descrição da morte da filha e à exibição das fotos da geração posterior que continua viva, mas Málca se prende à troca de código e me responde em hebraico, algo que evidencia o fato de que na sua visão de mundo essa parte da história é um trecho independente por si só, diferenciado do resto da narrativa.

Mihal: El destino no es en muestras manos. Malka: No. No, no, no, no. Ninguém sabe o que vai acontecer amanhã. As pessoas tem tanto orgulho, falam como... Tudo vanidades. Não resta nada. Ama...” (Michal: o destino não está em nossas mãos. Málca: No. No, no, no, no. Af echad lo iachol ladaat ma ikrê lo machar. Hagaavá sheish laanashim, shemedabrim... Hacol hevel hevelim. Lo nishar shum davar. Ama... (Não. Não, não, não, não. Ninguém sabe o que vai acontecer amanhã. As pessoas tem tanto orgulho, falam como... Tudo vaidades. Não resta nada. Mas...).

Nesse ponto da história a informante volta a falar em JE, e até o final do relato ela toma cuidado para não realizar outra troca de código, apenas incorporando aqui e ali algumas palavras em hebraico. A significativa transição ao hebraico na fala da informante ocorre, então, em um ponto sensível da história e serve para destacar a complexidade da trama; e os fenômenos lingüísticos reforçam e apoiam os fenômenos temáticos e de conteúdo.

\section{Troca de código na história de Levana $\operatorname{Sasson}^{27}$}

O JE é a língua materna de Levana Sasson, mas tendo nascido em Israel, e sendo mais jovem que Ester Levi e Malka Simha, os ciclos de vida dessa informante são mais israelenses e menos judeu-espanhóis do que o de suas amigas. Levana falava JE com a mãe, e depois da morte da genitora renovou o uso do idioma quando começou a participar do grupo de mulheres. Ela optou por se concentrar na figura de sua mãe logo no começo da história, que

\footnotetext{
${ }^{27}$ Nasceu em Jerusalém em 1942, aonde mora desde então. Fala hebraico, JE e um pouco de árabe.
} 
iniciou com a frase:

Me yamo Levana Sasson, yo nasi en [19]42 en Israel. Mi madre asuvio de la Turkia, kuando era de 17 anyos. (Me chamo Levana Sasson, nasci em [19]42, em Israel. Minha mãe emigrou da Turquia quando tinha 17 anos).

A narrativa continua com uma descrição da sua infância. Levana conta que sua mãe foi a única bebê que viveu dentre todos os irmãos e irmãs, e como sua vida também podia estar em perigo, realizou-se uma cerimônia com o objetivo de assegurar que seu destino mudasse para melhor. Ela foi entregue a uma família adotiva e teve seu nome mudado para Mircada (mercadoria, a vendida); ela foi criada pela mãe adotiva em vez da mãe biológica. Quando Levana fala dessa situação ocorre uma troca de código em sua fala, e ela se move do discurso fluente em JE para uma frase hebraica que se relaciona com o próprio fenômeno da troca de código, como ela o entende:

Meta le un otro nombre, Merkada,ke mozotros la vamos a merkar de ti, i beemet ansina bivio. No se si es ansina, cacha omrim. Aval, i... Beemet, ani, kashê li pitom ledaber beivrit sefaradit. (Ponha [dê] um outro nome a ela, Mercada, pois nós vendemos ela de você, e de fato assim ela viveu [ficou na vida]. Eu não sei se é assim, é isso que se diz. Mas... não... É verdade, eu, para mim é difícil de repente falar hebraico-espanhol).

Aqui a informante quer falar de sua mãe em JE, mas o conflito entre a língua que representa o mundo da mãe e o seu próprio mundo permanece como um obstáculo e ela diz: "para mim é difícil de repente falar hebraico-espanhol". Levana Sasson consegue se expressar bem em JE. Essa é sua língua materna e é com esse idioma que ela costuma relatar histórias populares longas, profundas e bem construídas. A dificuldade que ela enfrenta agora com o início de sua história pessoal não é relacionada com o falar JE, mas com a ligação que as duas línguas - o JE e o hebraico - representam na sua visão de mundo. De modo intuitivo ela agrupa o nome das duas línguas em um só termo - "hebraico espanhol" - e tenta elucidar para si mesma como contará a história usando essa mistura lingüística - algo que lhe parecia impossível. Mas ela prontamente se recupera e volta a falar da mãe em JE. A frase que vem a seguir, logo depois de ela expressar a dificuldade em falar "hebraico espanhol”, é: Mi madre, una sinema se puede azer de la istoria de eya. (Minha mãe, um cinema [filme] dá para fazer da história dela). O foco na mãe e na sua história - que é a âncora que estabiliza a história da filha - permite que Levana se solte da frase hebraica em que anteriormente se encontrava presa, e volte ao discurso fluente em JE, o que permite que sua história pessoal avance a partir desse ponto. 
Outro ponto em que o hebraico e o JE se misturam é o trecho do relato em que Levana faz uma comparação entre a vida da mãe e sua própria vida, entre a visão de mundo do passado e aquela que, em sua opinião, caracteriza a situação presente, e que forma a sua história pessoal. O trecho começa com uma descrição da situação da mãe internada no hospital pouco antes de morrer:

Levana: Es una dolor ke no kere amostrarte ke esta sufriendo, i 'sta kontando kol minei konsejas i shtuiot, para pasar el tiempo.

Mihal: Az eran mui emportante por pasar la vida, los kuentos?

Levana: Sim.

Mihal: No komo oy.

Levana: Az masheani omêret hahevdel bein az lehaiom. Shehaiu lanu chaiim lo kalim! At iodaát? Lalechet lehavi kol minei... lischov hacol mehashuk, ubli rechev ubli klum. Ubeemet, betsimtsum. Lo sheze haia shêfa. Veavadnu kashê. Ani zochêret. Miskena ima sheli, kama shepachot. Desha la fuersa para el tiempo tuyo, hi tamid haitá omeret li keshehaiti rotze laazor la. Aval, lo iacholnu. Hainu ozrim la. Vehainu mechabsim ita, vehainu megahatsim ita, veshotfim et habait. Menakim vekol ze. Aval hi haitá isha sheavdá kashe vehaita smechá kol hachaiim! At lo shamaat et haisha hazot!

Mihal: I esto oy, no ay.

Levana: No. No ay. Az esto [es] loke digo el evdel de az a oyi. Oyi tenemos mechonatkvisa, tenemos shoev-avak, tenemos... la djente madiach-kelim, i mikrogal... Entra i kita. I no... Beemet, veanachnu lo smechim kemo paam. Ani lo smecha kemo shehaiti paam. Afilu sheani ovêdet pachôt kashê meima sheli, zê lô...

Tradução:

Levana: É uma dor dessas que ela não quer mostrar que está sofrendo. E ela canta, e conta todo tipo de contos e besteira, para passar o tempo.

Michal: Então eram muito importantes para passar o tempo, as histórias?

Levana: Sim.

Michal: Não como hoje.

Levana: É exatamente o que eu estou dizendo, a diferença entre aquela época e hoje. Não tínhamos uma vida fácil. Sabe? Ir trazer todo tipo de... comprar tudo na feira, e sem carro, sem nada. $E$, de fato, no aperto. Não havia abundância. $E$ trabalhávamos duro. Eu me lembro. Coitada da minha mãe, o menos possível. Guarda sua força para o seu tempo.

Ela sempre dizia isso quando eu queria ajudá-la. Mas, não podíamos. Nós a ajudávamos. E lavávamos roupa com ela, engomávamos com ela, e varríamos a casa. Limpávamos e tudo mais. Mas ela era uma mulher que trabalhava duro e viveu a vida toda feliz! Você não ouviu essa mulher!

Michal: Eisso, hoje, não existe.

Levana: nNão. Não existe. É exatamente o que eu estou dizendo, a diferença entre aquela época e hoje. E hoje temos máquina de lavar, temos aspirador de pó, temos... as pessoas têm máquina de lavar louças, e microondas... [Todo tipo de coisa] entra e sai [fácil]. Tem. E... Na verdade, não somos tão felizes como no passado. Eu não sou tão feliz como já fui. Mesmo eu trabalhando bem menos duro que a minha mãe, isso não...

Esse é um exemplo de trecho de diálogo no qual fica difícil separar entre o hebraico e o 
JE. A troca de código é constante, a ponto de se tornarem parte inseparável da essência do diálogo em si. Em um momento a vida no passado e a figura materna é descrita em JE, enquanto que a vida presente é descrita em hebraico; e no outro momento parece que a dor pela perda da alegria que caracteriza a vida presente é representada em JE e a figura materna é descrita em hebraico. As palavras da mãe são citadas em JE, e a visão retrospectiva da filha sobre a vida da mãe é elaborada numa troca de hebraico e JE. A descrição da facilidade que caracteriza a vida contemporânea da dona de casa é dada parte em hebraico e parte em JE. A intensidade de fusão linguística exibida nesse trecho faz-nos sentir o poder da história pessoal narrada em linguagem judaica, com o hebraico moderno rodeando-a por ser o idioma social e cultural no qual a falante foi criada.

No início do trecho a informante diz uma frase em hebraico? "É exatamente o que eu estou dizendo, a diferença entre aquela época e hoje". Já no final do trecho ela retoma a frase que, dessa vez, é expressa quase que exclusivamente em JE: $\underline{\text { Az }}$ esto loke digo [es] el evdel de az a oy. A troca de código que ocorre no discurso não ocorre por falta de conhecimento do JE, mas por conta do processo mental refletido na história, um processo que ocorre quando o narrador tenta processar de maneira linguística a história de vida de sua mãe e integrá-la à sua história pessoal. A língua materna de Levana (não apenas como língua falada, mas também como metáfora para um sistema de relacionamento com sua mãe) é o JE. A experiência de vida no momento de ocorrência da história é hebraico.

Em um dialeto no qual não se pode separar a língua judaica e a língua hebraica, fica representada a força das narrativas pessoais que registrei para minha pesquisa. As trocas linguísticas ocorridas nas narrativas enfatizam a força delas, uma força que, pode-se supor, não refletiu totalmente o desenvolvimento narrativo das narrativas ditas apenas em JE ou hebraico.

\section{Conclusão}

Tamar Alexander-Frizer oferece um modelo para a análise da narrativa popular judaicoespanhola como expressão da identidade étnica. Um dos fatores que ela considera nessa análise é o JE falado. Segundo ela, o relato de uma história popular se dá dentro de um processo constante de diferenciação e integração, e, assim, quantos forem os grupos étnicos e as visões étnicas de mundo, assim serão os relatos das histórias populares. A história popular 
transmitida em JE representa as percepções coletivas dos criadores mais do que uma história semelhante narrada em hebraico. ${ }^{28}$ Essa definição também é relevante para a história pessoal narrada em linguagem étnica. Não tenho dúvida de que as escolhas das mulheres que formataram suas narrativas pessoais para a minha pesquisa - a escolha em fazer isso na língua de sua mãe, o JE, e não o hebraico - reflete, até certo ponto, o conteúdo das narrativas. A linguagem narrativa de grupo dirigiu suas falantes para o mundo das associações tradicionais - aquele mundo localizado no extremo étnico do espectro que vai da diferenciação à integração, e que Alexander-Frizer indica como relacionado à história popular judeuespanhola. Nesse contexto, o fenômeno da troca de código torna-se na linguagem do narrador, na qual o discurso em JE é abandonando e substituído pelo discurso hebraico, um fenômeno particularmente fascinante.

Galit Hasan-Rokem fala de três etapas na fala de histórias populares em Israel: a fala na língua étnica, a fala na etapa de transição (mistura entre o hebraico e a língua étnica) e a fala israelense em hebraico. ${ }^{29}$ Em outro local sugeri a inclusão de uma quarta etapa nesse modelo, que se pode chamar de pós-israelense. ${ }^{30}$ A fala desse tipo permite o retorno ao primeiro plano da língua judaica encurralado por um longo tempo. A cultura israelense contemporânea é bastante segura de si, e não teme a fala étnica. Dentro do quadro de pesquisa de campo que preparei com as informantes populares falantes de JE, foi marcado um encontro entre a representante da fala israelense (a pesquisadora, que respondia à história pessoal das informantes) e as representantes da fala étnica (as informantes). Nesse encontro eu vejo um território que permite a mescla da cultura do passado e do presente para criar uma narrativa pessoal em JE relacionada ao hebraico moderno de Israel em uma época na qual já havia os que falavam da morte da língua e cultura judaico-espanhola.

A análise das histórias pessoais das falantes de JE ilustra o fenômeno da troca de código, o que reflete a fusão do mundo tradicional judeu-espanhol e o mundo israelenese das informantes. Eu escolhi fazer isso através da análise das transições entre as duas línguas faladas pelas informantes - o JE e o hebraico - com ligação a um contexto temático: a relação das informantes com o contexto de relação entre mãe e filha da maneira como elas o interpretam, tanto em relação às suas mães como em relação às suas filhas.

\footnotetext{
${ }^{28}$ Alexander, Ahuv p. 45-54.

${ }^{29}$ Hasan-Rokem, p. 136.

${ }^{30}$ Held, Sipurê Am, p. 51.
} 
A relação entre mães e filhas ocupa um lugar de destaque na cultura judaico-espanhola, e seus agentes operam em direção a uma hermenêutica complexa. Tamar Alexander-Frizer descreveu e analisou o tratamento do grupo a esse respeito quando se trata da expressão de gênero nos provérbios. ${ }^{31}$ A discussão dos provérbios judaico-espanhois que refletem a relação entre mãe e filha pode ser resumida no provérbio que diz: "a filha e a mãe, como unha e carne" (la ija i la madre, komo la unya i la karne). Na questão e no contexto de nossa discussão aqui, podemos dizer que nas histórias pessoais das mulheres relativas às suas mães e suas filhas, o JE e a língua hebraica também são como unha e carne. Elas estão unidas entre si, e são utilizadas nas narrativas de forma alternada, sendo que a troca de código entre ambas produz uma expressão conjunta que representa um mundo misturado que este artigo quis ilustrar e discutir. O fato de a figura materna (a mãe das informantes ou elas mesmas como mães) ser chamada nas narrativas pelos termos ima, madre ou mama, lhe dá uma dimensão de profundidade e amplia o quadro de referência a ela e a suas opções de decodificação. Segundo Carol Mayers-Scotton, a troca de código é utilizada para representar uma identidade específica dos falantes frente ao ouvinte. ${ }^{32}$ A formação da imagem da mãe nas narrativas pessoais que temos diante de nós, e que se mostra por meio de um sistema de troca de código, é, de fato, parte de um sistema mais amplo de formação da identidade feminina das informantes.

Ilana Rozen insistiu que a troca de código é revelada nas narrativas pessoais como parte das estruturas de pensamento e que jazem por cima da expressão das narradoras. ${ }^{33}$ Com base em Mikhail Bakhtin, ela designa a estrutura imagética do mundo das mulheres, com ferramentas de expressão retiradas de diversas línguas, uma "polifonia de culturas e ideologias". ${ }^{34}$ De forma similar operam as línguas trocadas na boca das mulheres cujas narrativas pessoais foram usadas como substratos para este artigo. O JE e o hebraico israelense são línguas em contato, que refletem um sistema de culturas em contato. As trocas de código refletem uma mistura do mundo tradicional judeu-espanhol e do mundo israelense das mulheres falantes de JE.

A análise do fenômeno neste artigo foi feita no espírito da proposta de Monica Heller de descrever a etnografia do discurso dentro dos parâmetros da troca de código tanto no

\footnotetext{
${ }^{31}$ Alexander-Frizer Milim, p. 61-92.

${ }^{32}$ Mayers-Scotton, p. 151-152.

${ }^{33}$ Rozen, p. 103.

${ }^{34}$ Idem, p. 110.
} 
repertório pessoal das falantes, como no local ocupado por essas falantes na rede comunitária e social na qual vivem. O idioma JE e o idioma hebraico usados aqui e ali de maneira alternada nas narrativas pessoais das mulheres judias-espanholas ajudam as falantes a expressar as imagens de mundo multifacetadas que possuem.

Peter Auer, um dos pesquisadores centrais que se dedicou ao fenômeno da troca de código do ponto de vista linguístico, recentemente tentou avaliar novamente o fenômeno, e chegou à conclusão de que é preciso expandir o ponto de vista da troca de código para além das fronteiras linguísticas nos quais ele ocorre:

[...] a abordagem sociológica, bem como a abordagem gramatical, não reflete a disposição dos fenômenos determinados observados no discurso bilíngue. A diferença ocorre exatamente nos padrões do "movimento" de troca de código (ou em "unidades de intenção") em que cada um apresenta "unidades estruturais" completas em termos de sua estrutura sintática. ${ }^{35}$

Neste artigo sugeri um método de análise da troca de código como um sistema que se estende para além do âmbito da concepção sócio-linguística e sintática: a análise da troca de código foi baseada na definição de fenômenos linguísticos como sendo estratégias narrativas que sinalizam fenômenos extra-linguísticos aos discursos nos quais estão inseridos. A análise mostrou como o bilinguismo das mulheres que narram suas narrativas pessoais em judeuespanhol e que misturaram nelas transições ao hebraico reflete uma imagem de identidade em camadas, quando a troca de código é de fato utilizada, como proposto por Auer, como unidades de intenção e de propósito.

${ }^{35}$ Auer, reavaliação, p. 3. 


\section{Referências}

Alexander-Frizer, Ahuv Tamar Alexander-Frizer, Maassê Ahuv Vachetsi, Hasipur Haamami shel Iehudê Sefarad, Jerusalém 5760.

Alexander-Frizer, Milim Tamar Alexander-Frizer, Milim Mashbiot Milechem, Lechecer Hapitgam Hasefaradi-Iehudie, Jerusalém e Beer Sheva 5764.

Auer, Artigo revisado Peter Auer, "Bilingual Conversation revisited" in: Peter Auer, (ed), Code-Switching in Conversation: Language, Interaction and Identity, London 1998, pp. $1-24$

Auer, Bilinguismo Peter Auer, Bilingual Conversation, Amsterdã / Filadelfia 1984

Benbassa e Rodrigue Ester Banbasa e Aharon Rodrigue, Iehudê Sefarad Beartsot Habalcan Bameot Hachamsh Essrê-Haessrim, Jerusalém 1995.

Blom e Gumperz Jan-Petter Blom and John, Joseph Gumperz, "Social Meaning in Structure: Code-Swithching in Norway", in: John, J. Gumperz and Dell Hymes (eds.), Directions in Sociolinguistics: the Ethnography of Communication, Nova Iorque 1972, pp. 407-434.

Bunis David Bunis, Haiessodot Haivriim Vehaaramiim Besefaradit-haiehudit Hachadash ב(Judezmo), Jerusalem 5753.

Hasan-Rokem Galit Hasan-Rokem, “Cheker Taalichi Hatemurá Basipur Haamami”

Mechacrê Ierushalaim Befolclor Iehudi 3 5742, p. 129-137.

Koen-Sarano, Konsejas Matilda Cohen-Sarno, Konsejas i Konsejikas: Sipurim Umaassiot Mehaolam Haiehudi-sefaradi, Jerusal’m 5754.

Koen-Sarano, Kurtijo Matilda Koen-Sarano, El Kurtijo Enkantado - Hachatser Hakesumב: Agadot Vesipurim Min Hamassoret Haiehudit-Sefaradit, Jerusalem 5763.

Koen-Sarano, Joha Matilda Cohen-Sarno , Joha: Ma H תOmer? Sipurê Am IehudiimSefaradiim, Jerusalém 5752.

Cohen-Sarno, Legendas Matilda Cohen-Sarno, Legendas: Agadot Ve Sipurê Mussar Min Hamassóret Haiehudit-Sefaradit, Jerusalém 5759.

Gumperz John, Joseph Gumperz, Discourse Strategies, Cambridge 1982

Harris Tracy Harris. "Code-switching in Contemporary Judeo-Spanish", in: Stillman, Y.K. \& Stillman, N. (eds.), From Iberia to Diaspora, Studies in Sepharadic History and Culture, Leiden 1999 
Held, Boi Michal Held, Boi Essaper Lecha / Ven ti cuntare: iun rav techumi besipurim ishiim shel messaprot amamiot dovrot sefaradit-iehudit (Ladino), Jerusalem, 5769.

Held, Sipurê Am Michal Heled, "Onde estan todas las consizas" (Onde estão todos os causos?): Al Hishtacutam Shel Sipurê Am Besipurá Haishi Shel Doveret Seferadit-iehudit Mirushalaim”, Mechacrê Ierushalaim Befolclor Iehudi 23 5765, p. 39-60.

Heller Monica Heller, "Where do we go from here?", in: Monica Heller, (ed.), Codeswitching, Anthropological and Sociolinguistic Perspectives, Berlim, Nova Iorque \& Amsterd 71988, pp. 265-271

Mayers-Scotton Carol Mayers-Scotton, Social Motivation for Codeswitching, Evidence from Africa, Oxford 1993

Milroy e Muysken Lesely Milroy and Pieter Muysken, "Introduction: Code-Switching and Bilingualism Research”, in: Lesely Milroy and Pieter Muysken, (eds.), One Speaker, Two Languages, Cross-disciplinary Perspectives on Code-Switching, Cambridge 1995, pp. 1-14

Poplack Shana Poplack, "Sometimes I'll start a sentence in Spanish Y TERMINO EN ESPANOL: Toward a typology of code-switching”, in: Linguistics 18 Vol 7/8, 1980, pp. 581618

Rodrigue e Socolov Ora Rodrigue-Schwarzwald e Socolov, Milon Lemunch 7 Balshanut Vedicduc, Even Iehuda 5752.

Rozen Ilana Rozen, Achot Letsarב, Masa Al Sipur Chaiechen Shel Nitsolot Shoa Mehungaria, Beer Sheva, 5763.

Weinreich Uriel Weinreich, Languages in Contact, Findings and Problems, The Hague 1963 